\title{
An introduction to computerised analysis of qualitative data
}

\author{
Merike Darmody ${ }^{\mathrm{a} \star}$ and Delma Byrne ${ }^{\mathrm{b}}$ \\ ${ }^{\mathrm{a}}$ The Economic and Social Research Institute, Ireland; ${ }^{\mathrm{b}}$ University of Edinburgh, Scotland
}

\begin{abstract}
Over the last two decades there has been an increase in the use of qualitative research, particularly in the human sciences. Such a move has resulted in an increasing number of researchers across disciplines using various types of qualitative software specially designed for managing text and facilitating analysis of qualitative data. However, we feel that limited information is available on the nature and practical use of these programmes in the Irish context. This has led to various misconceptions regarding the use of such programmes. In addition, international literature has highlighted the importance of making the qualitative research process more transparent in terms of describing in detail the analytical procedures applied in qualitative research. This article seeks to open up the debate surrounding qualitative data analysis and provoke discussion about the use of qualitative software packages in educational research. Based on a mixed-methods educational research project involving a substantive qualitative component, this article explores the joy and despair associated with using Qualitative Solutions Research (QSR) Non-numerical Unstructured Data: Indexing, Searching and Theorizing Version 6 ('N6 software'), and aims to dispel some of the myths that exist around using such software.
\end{abstract}

\section{Introduction}

Depending on the nature of the research project and the amount of data and resources available, qualitative data analysis can often be very labour-intensive and time-consuming. This is partly due to the fact that qualitative data analysis is not a mechanical procedure. Rather, it can be considered the 'dynamic, intuitive and creative process of inductive reasoning, thinking and theorising' (Basit, 2003, p. 143). Qualitative analysis requires a substantial amount of time to make sense of one's data by careful reading, coding (categorising), re-reading and re-coding. This activity usually involves hours spent with the data exploring emerging themes and concepts and the links between them. In order to facilitate data management and analysis in qualitative inquiry, several software programmes have been created over the years.

Despite the dearth of detailed descriptions of the processes involved in computerassisted qualitative analysis in the Irish context, this is by no means a novel approach. Over the last two decades international qualitative research has witnessed an

^Corresponding author. The Economic and Social Research Institute, 4 Burlington Road, Dublin 4, Ireland. Email: merike.darmody@esri.ie 
increasing use of software specially designed for managing text and facilitating analysis of qualitative data. ${ }^{1}$ The first specially designed qualitative software programmes were introduced back in the 1980s (Richards \& Richards, 2002). Parallel to the growth of qualitative research, special programmes such as N6, NVivo, Atlas/ti, Qualrus, HyperRESEARCH, MAXqda, MAXdictio and QDA Miner, amongst others, were designed to manage large textual data sets. These programmes are generally referred to as Computer Assisted Qualitative Data Analysis Software (CAQDAS). ${ }^{2}$ In addition, recent years have witnessed constant updating of the existing programmes to bring them more in line with the needs of researchers. Although they are now widely available, researchers seem to approach them with caution, being unsure of the possibilities and limitations of using such software (Dohan \& Sanchez-Jankowski, 1998). In addition, the existing literature lacks serious critique about the use of different types of qualitative software that researchers could find beneficial (MacMillan \& Koeing, 2004). These possibilities and limitations will be discussed in the following sections of this article, with specific reference to Qualitative Solutions Research (QSR) Non Numerical Unstructured Data: Indexing, Searching and Theorizing Version 6 (NUDIST), hereafter referred to as N6 software as one of the more common software programmes available in Ireland.

\section{Qualitative data software: a straightjacket or a liberator?}

The creation of software presents its own challenges for qualitative data analysis and such issues have yet to be widely debated in the research literature (see Holbrook \& Butcher, 1996). Indeed, an ongoing debate in the literature relates to whether the software actually aids the analysis of qualitative data in any way. Internationally, since the advent of computerised software, there has been a general expectation among researchers that specialised software can notably facilitate data management and analysis (Becker et al., 1984; Conrad, 1984). However, there is a paucity of literature detailing the processes involved in using the software and the need for a critical evaluation of its suitability in qualitative research remains obvious (Richards \& Richards, 2002) and has added to the confusion about its use, whereby people have different opinions about its usefulness. Indeed, some researchers can mistake software for the methodology rather than a methodological tool (MacMillan \& Koeing, 2004).

From our experience, we feel that these conflicting opinions and the suspicion regarding the use of CAQDAS are often caused simply by a limited knowledge regarding these programmes and their capabilities as well as by insufficient training in the use of qualitative research methods on the part of the researcher. It could be argued that in Ireland, access to training in the use of qualitative software is still limited, incorporated in most cases in master's programmes of applied social sciences. Some training is, however, provided by software developers. Unfortunately, these factors lead to unrealistic expectations of software capability (Sin, 2003). Researchers with little experience in using such software are often unsure whether it 
is a tool for data analysis or whether it 'somehow drives the research' (Crowley et al., 2002).

Moreover, certain confusion is also caused by a lack of detailed information in research literature regarding the qualitative methods that researchers have used in their work. In other words, literature detailing 'how purpose, data and analytic technique fit together' in qualitative research has a tradition of being scant (Anfara $e t$ al., 2002; Morse \& Richards, 2002). In the absence of detailed description of the research processes, it may be difficult for a novice researcher to understand both the rationale for choosing a particular approach in qualitative data analysis as well as practical use of the software. Uncertainty may lead to unrealistically high levels of expectation about CAQDAS use. It also becomes harder to maintain rigour in qualitative enquiry.

A pending question in the literature pertaining to qualitative software relates to whether the use of qualitative software makes the research process more transparent and whether the validity and reliability of results can be maintained. Rigour and credibility of qualitative research have been widely debated in the international literature (Maxwell, 1992; Kelle et al., 1995; Adcock \& Collier, 2001; Morse \& Richards, 2002). For those who believe that qualitative research is interpretative and subjective (for example, see Lincoln \& Guba, 1985), it has been suggested that validity and reliability should be treated differently in qualitative research (Morse \& Richards, 2002). This article argues that qualitative enquiry can be as rigorous as quantitative enquiry. In both cases the rigour depends on the researcher and whether he or she has the required skill and knowledge necessary for the work at hand (Morse \& Richards, 2002).

For some, the concern about validity and reliability in qualitative analysis has led to the belief that the use of computer programmes in qualitative analysis somehow adds a 'sheen of scientific rigour' to the process ( $\operatorname{Sin}, 2003$ ). We argue that this may be a reaction to the criticism of some researchers who approach qualitative research with a 'quantitative mindset' and question rigour and validity in qualitative research. Others argue that the use of such software has reopened debates over the reliability and scientific attributes of qualitative methods (Crang et al., 1997). We follow Morse and Richards, who highlight the importance of using appropriate sampling techniques, being responsive to strategies that are not working, pacing the project appropriately, and ensuring reliability of coding. If it addresses these issues, the qualitative enquiry can be considered valid, reliable and rigorous. Better understanding of the technical side of using specific software further facilitates maintaining rigour in qualitative enquiry. In order to demystify the use of computing in qualitative analysis, the following sections show how qualitative software programmes can facilitate the analysis, allow easy access to the data, as well as enable constant re-ordering of the material as the ideas about the research topic become clearer. In this context the following sections provide an introduction to using N6 in qualitative research. 


\title{
N6: up close and personal ${ }^{3}$
}

The software comprises an internal database, which means that all individual data files (such as interview transcripts) are imported into a single 'Project', a 'core' of N6 where all the files are stored. The programme uses the document and node functions as central organising concepts (as discussed below). There are two main elements to the database. First, the 'Document Explorer' houses all 'datafiles' (hereafter called documents) for viewing and searching. ${ }^{4}$ The researcher can select the minimum unit of text (by paragraph, line or word) in order to facilitate coding depending on the nature of the project. Having imported plain text data files into the Project, these documents can then be viewed in the Document Explorer (see Figure 1 in Appendix) and annotated before any coding takes place. Second, the 'Node Explorer' ${ }^{5}$ links the coding schema and documents through the use of nodes. Nodes differ according to each qualitative analysis and can represent people, places, objects, themes and general results of analyses. A node can be a theme that has either emerged from the data or is pre-assigned based on existing literature.

Qualitative analysis using N6 begins by viewing documents in the Document Explorer, identifying information of interest, coding it and lifting out coded segments from their source position, into nodes, with the use of the coding bar. It is important to remember that coding is 'not the analysis itself but a preliminary to make the task of analysis manageable' (Potter \& Wetherwell, 1994, p. 52). Output reports can be used in order to show how a whole document has been coded. The nodes can either be organised into hierarchical trees, thus enabling more efficient use of the databases, or used non-hierarchically. The flexibility of using N6 can be summed as follows:

\begin{abstract}
Nudist's more systematic nature comprises a number of features that aid more complex project work. It is easier to keep track of progress on complex projects with the project management emphasis. It is suited to the handling of different data types, for example data can be linked by case; or longitudinal data can be analysed by time of data collection. Where a project employs both qualitative and quantitative data Nudist has a number of features for importing and utilising the quantitative facts known about a case in analysing the qualitative data. Nudist allows multiple researchers based at different sites, even those using different hardware (PC or Mac) to work on coding separately and then combine the work done at stages using the Merge function. (Barry, 1998, paragraph 9.11)
\end{abstract}

With a variety of functions available, N6 greatly facilitates the processes involved in dealing with large amounts of textual data. The processes and issues relating to coding involved in using N6 are discussed in more detail in the following section.

\section{Approaches to qualitative data analysis using N6 software}

What can the software do and to what extent do its functions constitute analysis? It has been argued that serious critiques of whether qualitative data analysis software transforms the analytic process are lacking in the methodological literature (Richards, 2002). To reiterate, coding and categorising of the collected data are 
central to processes in qualitative data analysis irrespective of the software being used. However, there seem to be misconceptions among some researchers that analysis is achieved by simply organising the data into hierarchical categories within the software programme. In line with other authors, we stress that the software allows data to be systematically analysed, whereby themes are developed aiding theorising, and it also helps to see the emerging ideas in a wider theoretical context of the existing literature. The essence of qualitative analysis can be summed up as follows:

If the researchers' observations and participants' accounts are explored within the theoretical body of social support literature, the study can be tried against other situations, and moves from description to analysis. (Morse \& Richards, 2002, p. 150)

It is important to make the point that analysis is not separate from coding, while at the same time it is not synonymous with it. Coding facilitates thinking and theorising about the research topic to develop themes, thus aiding the analysis. A common error made by novice users of such software is to mistake qualitative coding for quantitative coding. The latter is described by Morse and Richards (2002, p. 127) as a process where researchers 'want to ensure that they have the right numbers down and have no omissions'. In other words, this is largely seen as a mechanical process. However, mechanical coding or, in other words, utilising a 'code now and analyse later' approach in qualitative analysis can lead to both excessive coding and the risk of failing to develop the conceptual analysis (Strauss \& Corbin, 1998). In order to avoid excessive coding, the researcher should keep in mind the research design and the theoretical framework in order to decide what information is useful to code, depending on the research questions and methods chosen. Qualitative coding is, first and foremost, interpretative (Morse \& Richards, 2002).

\section{Theory building using N6 software}

How does qualitative software aid theory building? Whether the data analysis is qualitative or quantitative, researchers generally approach the research through the guidance of a theoretical framework or a conceptual model as part of the research design. The theory that qualitative researchers attempt to construct relates to 'low level theory', which is applicable to immediate and specific situations, rather than grand or formal theories, which are of 'greater abstraction and applicability' (Creswell, 1997). However, the 'low level theory' is very useful in improving one's understanding of the phenomena under investigation.

Based on existing literature one can identify two broad approaches that qualitative researchers adopt in order to make sense of their data before coding takes place. On the one hand, qualitative researchers tend to use inductive analysis of data, meaning that the critical themes emerge from the data itself (Patton, 1990; Mason, 1996). This grounded theory ${ }^{6}$ approach emphasises the generation of theory from the data and focuses a priori on building theory as the only target of the research project. On the other hand, many other qualitative studies focus primarily on meaningful description and regard the theoretical explanation as secondary to meaningful 
description. This type of qualitative research can then begin with a predefined set of themes and concepts, which have been derived from the research literature. ${ }^{7}$ Again, in this context it is important to note that the approach to systematic coding undertaken by qualitative researchers should be informed by the overall research design.

The coding in qualitative research represents theoretical categories applied to the field/issue under study (Kelle, 1997). This method helps the researcher to ask questions, to compare across data, to change or drop categories and to make a hierarchical order out of them if necessary (Tesch, 1990). The software then aids theory building by its ability to ask questions about how a text segment was coded but also about the coding of the whole file or other text segments. In essence, the software aids theory building through the coding structure with the use of saving and reusing the results of searches as well as storing and editing memos.

Using N6 software, various approaches can be utilised in coding the data. First, one can begin by Base Data Coding or Demographic Coding, whereby coding is used to record information about the individuals being interviewed or topics being discussed. Conventionally this data is stored in Tree Node 1. For example, the code 'Female' could contain all transcripts belonging to Females. The beauty of Base Coding is that it allows demographic data to be exchanged between N6 and other programmes such as spreadsheets, databases and statistics programmes and allows use of 'matrix 'and 'vector' functions (similar to cross tabulations) to explore emerging patterns in the data. Second, data can be coded according to themes or categories as discussed above. After using open coding for creating broad themes, one can then move to fine coding as the ideas about the topic/issue become clearer. The actual theoretical coding procedure can be undertaken using tools in N6 such as Text Search, Text Retrieve, Node Search, Memos and Command Files. The software allows for questions to be asked not just about the coding of a text segment but about the coding of a whole file or of other text segments. Further questions can then be asked about the coding structure by saving and reusing results of searches, thus building on results iteratively. However, it has been argued by software developers that theory building using qualitative software remains a continuing challenge in terms of critical discussion of the theory-building capabilities of the software (Richards, 2002).

\section{Empirical example: The transition year programme: an assessment}

This section provides an example of the process involved in the analysis of qualitative data using N6 in educational research. The study was a large-scale project commissioned by the Department of Education and Science which set out to address gaps in existing research relating to transition year (TY) provision (see Smyth et al. , 2004). Undertaken by researchers at the Economic and Social Research Institute (ESRI), the aim was to unpack the educational processes associated with TY provision. In this example, the main question being addressed by the qualitative 
component of the research related to how school principals, teachers and students viewed the TY programme according to different types of TY provision. The method of inquiry that was selected as most appropriate in this example was meaningful description in order to capture the perceptions of the main stakeholders involved in the programme. The qualitative component formed part of a mixed-methods approach utilising both qualitative and quantitative techniques.

\section{Process: from data entry to final analyses}

Why was it deemed appropriate to use N6 in this research? A number of factors led us to using N6. First, given the size of the sample population, analytical strategy made it clear that software would be useful, given its ability to handle large amounts of data. Second, one member of the research team already had practical training and experience of using N6. Thus, given the size of the project and previous experience and training in the use of the software, N6 was chosen.

In terms of the sample population, in total twelve secondary schools were selected for in-depth case studies based on their TY provision. Audio-taped semi-structured interviews were conducted with principals, guidance counsellors and TY coordinators, resulting in 22 interviews. These were also complemented by focus group interviews with 88 students. Furthermore, a number of topics addressed during the interviews (which were based on earlier work conducted on school effectiveness as well as gaps in previous research relating to TY) resulted in large amounts of material for analysis.

Stage one involved entering data into N6. Each of the transcribed interviews was imported into a separate text document in N6 from a standard Word document. A title and header was allocated to each text document using the Document Explorer. In this instance, header information contained school-level information based on how the case-study schools were sampled as well as other relevant information pertaining to the individual being interviewed (such as gender and so on). The schools were initially identified from a national schools database, which allowed for a meaningful selection of schools with different student intakes (in terms of social class background and prior academic ability) along with different levels of exam performance and school drop out (controlling for student intake). Interviewees were then selected within these schools. This process was carried out for each interview imported into $\mathrm{N} 6$ and we found that it made identification of each transcript visually easier. Within a relatively short amount of time, all transcripts were imported into the software. The next task was to develop a method for structuring the data within N6.

Stage two involved conceptual work on how to structure the data and initial coding tree in N6. At this stage nodes were developed using the Node Explorer. Tree nodes in this case were divided into two major nodes - base data and themes. The following section outlines how base data were conceptualised for this particular example. In this project base data contained information pertaining to both the individual and the school the individual had been attending. This meant that all data were initially 
coded according to these criteria. (The coding tree and sequence for base data can be seen in the Appendix, Figure 2.) This coding scheme offered individual information on what was known about the speaker (labelled 'interviewee'), such as their status in the school and their gender, but also school information (labelled 'school') in terms of school characteristics and TY provision. The rationale for such an approach was linked to the quantitative aspect of the study; the researchers had already found significant differences in patterns of TY take-up across schools. Furthermore, most of the existing literature surrounding TY participation and educational interventions dealt with the content (Department of Education, 1996) and perceptions of the programme (TYCSS, 2000) and educational outcomes (Millar \& Kelly, 1999). However, we were unclear as to how these perceptions and outcomes differed across students in TY programmes within schools. In a nutshell, the rationale for having individuals and schools as base data arose from the questions being addressed in the research design, relating to perceptions both of the individual (according to their role in the school) and of individuals in different types of schools (according to the characteristics of the school). By utilising this approach, the software was already aiding the process of analysis by allowing for the integration of textual and statistical analysis in a project using mixed-methods data while retaining the richness of the qualitative data.

Stage three involved coding the interviews. The second major node created was labelled 'Themes'. For the themes, we began by consulting the semi-structured interview schedule that we had used as a guide when conducting the interviews. These questions had been informed by the existing research literature. The interview schedule provided an outline of the topics that the interviewees were questioned about and so gave us an ideal starting point for initial categorising and coding with reference to the research design. And so began the process of systematic analysis. The approach to data analysis taken meant that all matters regarding, for example, 'work experience' or 'perceptions of a particular aspect of the programme' could be placed in a generic node-storing place and comments compared across teachers and students. The frequency of coding of certain themes could be explored by comparing coding with base data. However, the process of data analysis did not stop when all relevant data had been coded into categories. Upon re-reading and with further analysis of the transcripts in N6, further themes and concepts began to emerge from the data which had not been evident from the interview schedule. For example, the concept of 'school ethos' emerged clearly from the data even though it had not been systematically explored in the interview schedule. We found that systematic analysis of the coding then not only allows for the exploration of themes and theoretical frameworks informed by the research design but also allows themes to continue to emerge from the wider context of the data.

We discovered that the software greatly facilitates the process of analytic coding and re-coding in a number of ways. First, through the use of software, the researcher had unlimited ability to code text in an orderly and timely manner. This is easily managed given that $\mathrm{N} 6$ allows refining the coding of the data by adding more 'child' nodes onto 'adult' nodes. Second, the software greatly facilitated linking text with 
codes, retrieving text according to the category within which it was coded as well as retrieving the context of the text. The product of the analysis was a number of main categories, which included several subordinate categories. The coding tree for themes is outlined in the Appendix.

Conceptually, the coding scheme was very much linked to the research design; the content of the semi-structured interviews initially gave conceptual guidance and reduced the possibility of excessive coding. At the same time this method allowed for additional issues and themes to emerge as the data were re-coded and re-analysed. The coding of base data provided a systematic method of comparing perceptions of individuals with other individuals (e.g. staff and students), but also with individuals within other schools. This two-level approach allowed unpacking of the educational processes associated with TY. While it laid a foundation for coding through the use of a theoretical framework, it also facilitated the development of themes and concepts from the data itself.

On a practical level, the use of N6 greatly facilitated managing and storing the large numbers of interviews, being a visually useful and efficient tool. Technically, we found no difficulty in transferring qualitative data into software: technically, it is no different from converting a Word document into a pdf file or importing an Excel spreadsheet into SPSS. Practically, we found that as the key concepts became clear through re-coding, so too did the chapters for our research project.

\section{Discussion}

This article serves as an introduction to analysing qualitative data with the help of specially designed software programmes. In the introduction we have highlighted the development and availability of such programmes over the years in order to respond to the difficulties experienced by researchers undertaking qualitative research, which mainly manifests itself in extremely labour-intensive and time-consuming work, given the nature of this type of research.

Taking into account the paucity of literature in the area, we have discussed the role qualitative software plays in the research process, drawing on the experiences of working with N6 while exploring issues around the TY programme in Ireland.

First, the project design necessitated use of a large number of semi-structured interviews in order to explore the perceptions of students and key personnel in the case-study schools with regard to the usefulness of the programme. After familiarising ourselves with a number of qualitative software programmes we decided to go with N6 due to its capability of handling large datasets and easy-to-follow instructions about the technical use of the programme. Overall, we found N6 easy to operate from the perspective of sorting and coding the data. The analysis was greatly facilitated by being able to gain easy access to the data, comparing across the categories (base data and themes or between the themes), while recording emerging ideas. Hence the purpose, data and technique fitted together, enabling us to gain better understanding about the perceptions of the main stakeholders involved in the TY programme. 
While we found that using N6 aided us in our analysis, we acknowledge that there is a concern among some authors that inexperience in using qualitative software may lead to unrealistic expectations about the use of CAQDAS. In this context it is important to remember that using qualitative software is not analysis. Qualitative software is a methodological tool that facilitates analysis to a great extent by allowing easy access to the data for continuous reviewing and theory building. Analysis, on the other hand, consists of coding, categorising and theorising in the framework of a theoretical body of literature and is not merely a description. Direct links in the N6 software between coded segments and the full transcript meant that data were not separated from their context and could be used in all their richness and complexity. However, we would caution researchers frequently referring back to the original transcript to remind themselves of the context the data was drawn from. In addition, researchers should be cautious when collecting data; while the use of software facilitates data analysis, it does not justify and cannot overcome a poorly designed research project. Coding often presents its own issues. In the research project described in this article we coded certain data and not 'everything in sight'. Being clear about the aims of the research project and research questions helps to identify relevant data and hence speeds up the coding process.

In sum, we found that N6 is a very useful tool in data analysis once purpose, data and technique have been well thought out. It is hoped that the detailed description of steps taken in using N6 in a research project provides useful advice for researchers considering the adoption of computerised analysis of qualitative data in their research.

\section{Notes}

1. For further reading on technological developments concerned specifically with data gathering, consult Gibbs et al. (2002).

2. For more details on CAQDAS and the CAQDAS networking project, follow the link http:// caqdas.soc.surrey.ac.uk/

3. For a demonstration version of N6, follow the link www.qsrinternaional.com

4. Interview transcripts and other external documents are reformatted into plain text data files (.txt).

5. The Node Explorer window is organised on the same principle as Document Explorer and has similar functions allowing you to browse and gain easy access to the node.

6. In fact, Strauss and Corbin (1998) link the growth in the use of the grounded theory methodology to the use of qualitative software and outline its prevalence in the disciplines of education, nursing, psychology and sociology.

7. Further discussion of these types of theoretical analysis can be found in Shkedi (2004) and Creswell (1997).

\section{References}

Adcock, R. \& Collier, D. (2001) Measurement validity: a shared standard for qualitative and quantitative research, American Political Science Review, 95(3), 529-546. 
Anfara, V. A., Brown, K. M. \& Mangione, T. L. (2002) Qualitative analysis on stage: making the research process more public, Educational Researcher, 31(7), 28-38.

Barry, C. A. (1998) Choosing qualitative data analysis software: Atlas/ti and Nudist compared, Sociological Research Online 3(3). Available online at: http://www.socresonline.org.uk/ socresonline $/ 3 / 3 / 4 / \mathrm{html}$ (accessed 16 March 2006).

Basit, T. N. (2003) Manual or electronic? The changing role of coding in qualitative data analysis, Educational Researcher, 45(2), 143-154.

Becker, H. S., Gordon, A. C. \& LeBailly, R. K. (1984) Field work with the computer: criteria for assessing systems, Qualitative Sociology, 7(1/2), 16-33.

Conrad, P. (1984) Computers and qualitative data: editor's introductory essay, Qualitative Sociology, 7(1/2), 3-15.

Crang, M. A., Hudson, A. C., Reiner, A. M. \& Hinchliffe, S. J. (1997) Software for qualitative research: 1. Prospectus and overview, Environment and Planning A, 29, 771-787.

Creswell, J. (1997) Qualitative inquiry and research design: choosing among the five traditions (Thousand Oaks, CA, Sage Publications).

Crowley, C., Harre, R. \& Tagg, C. (2002) Qualitative research and computing: methodological issues and practices in using QSR NVivo and Nud*ist, International Fournal of Social Research Methodology, 3, 193-197.

Department of Education (1996) Transition year programme 1994-1995: an evaluation by the inspectorate of the Department of Education (Dublin, Department of Education).

Dohan, D. \& Sanchez-Jankowski, M. (1998) Using computers to analyse ethnographic field data: theoretical and practical considerations, Annual Review of Sociology, 24, 477-498.

Gibbs, G. R., Friese, S. \& Mangabeira, W. C. (2002) The use of new technology in qualitative research, Forum Qualitative Social Research (3)2. Available online at: http://www.qualitativeresearch.net/fqs/ (accessed 16 March 2006).

Holbrook, A. \& Butcher, L. (1996) Uses of qualitative data analysis in educational research: the literature, the hard questions, and some specific research applications, The Australian Educational Researcher, 23(3), 55-80.

Kelle, U. (1997) Theory building in qualitative research and computer programs for the management of textual data, Sociological Research Online 2(2). Available online at: http:// www.socresonline.org.uk/socresonline/2/21.html (accessed 16 March 2006).

Kelle, U., Prein, G. \& Bird, K. (1995) Computer-aided qualitative data analysis: theory, methods and practice (London \& Thousand Oaks, CA, Sage Publications).

Lincoln, Y. S. \& Guba, E. G. (1985) Naturalistic inquiry (Beverly Hills, CA, Sage Publications).

MacMillan, K. \& Koeing, T. (2004) The wow factor: preconceptions and expectations for data analysis software in qualitative research, Social Science Computer Review, 22(2), 179-186.

Mason, J. (1996) Qualitative researching (London, Sage Publications).

Maxwell, J. A. (1992) Understanding validity in qualitative research (Thousand Oaks, CA, Sage Publications).

Millar, D. \& Kelly, D. (1999) From junior to leaving certificate: a longitudinal study of 1994 junior certificate candidates who took the leaving certificate examination in 1997 (Dublin, ERC/ NCCA).

Morse, J. \& Richards, L. (2002) Read me first: a user's guide to qualitative methods (London, Sage Publications).

Patton, M. (1990) Qualitative evaluation and research methods (Newbury Park, CA, Sage Publications).

Potter, J. \& Wetherwell, M. (1994) Analysing discourse, in: A. Bryman \& R. G. Burgess (Eds) Analysing qualitative data (London, Routledge), 47-66.

Richards, L. (2002) Qualitative computing: a methods revolution? International fournal of Social Research Methodology, 5(3), 263-276.

Richards, L. \& Richards, T. (2002) Qualitative computing and qualitative sociology: the first decade. Available online at: www.qsr.com.au (accessed 16 March 2006). 


\section{M. Darmody \& D. Byrne}

Shkedi, A. (2004) Second-order theoretical analysis: a method for constructing theoretical explanation, International fournal of Qualitative Studies in Education, 17(5), 627-646.

Sin, C. H. (2003) Using NUD ${ }^{\star}$ ist N6 in a large-scale national evaluation project: a multi-site team experience, paper presented at Strategies in Qualitative Research (Institute of Education, University of London).

Smyth, E., Byrne, D. \& Hannan, C. (2004) The transition year programme: an assessment (Dublin, The Liffey Press in Association with the Economic and Social Research Institute).

Strauss, A. \& Corbin, J. (1998) Grounded theory methodology: an overview, in: N. D. Denzin \& Y. S. Lincoln (Eds) Strategies of qualitative inquiry (Thousand Oaks, CA, Sage Publications), $158-183$.

Tesch, R. (1990) Data distillation qualitative research: analysis types and software tools (Basingstoke, Falmer).

TYCSS (Transition Year Curriculum Support Service) (2000) Support active teaching and learning: project work (Blackrock Education Centre, Dublin, Transition Year Curriculum Support Service).

\section{Appendix}

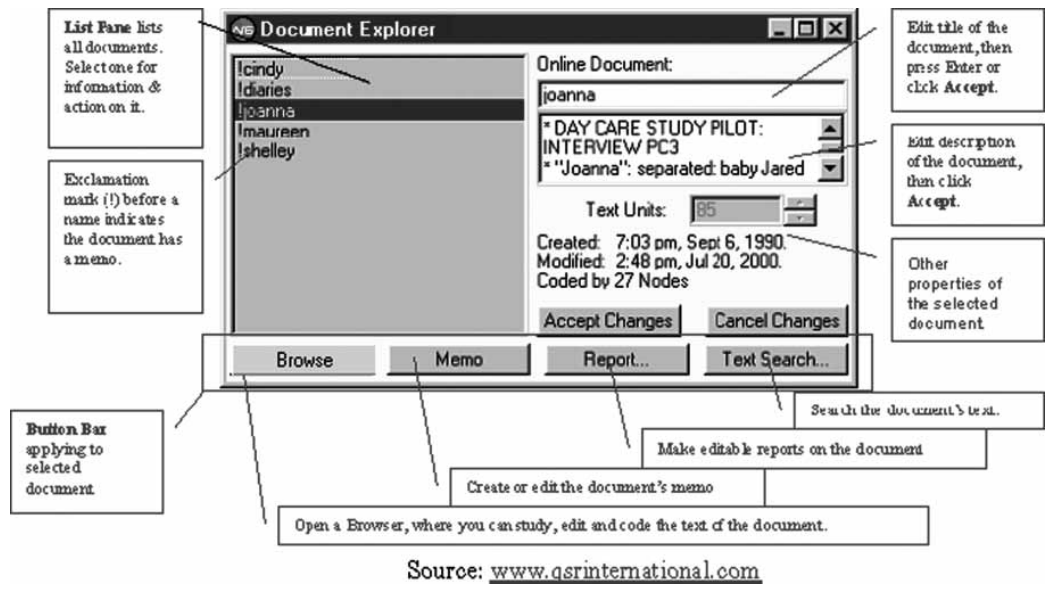

Figure 1. Screen shot of Document Explorer 
(1)

$(1,1)$

$(1,1,1)$

$(1,1,2)$

$(1,2)$

$(1,2,1)$

$(1,2,1,1)$

$(1,2,1,2)$

$(1,2,1,3)$

$(1,2,2)$

$(1,2,2,1)$

$(1,2,2,2)$

$(1,2,3)$

$(1,2,3,1)$

$(1,2,3,2)$

$(1,2,3,3)$

$(1,2,4)$

$(1,2,4,1)$

$(1,2,4,2)$

$(1,2,5)$

$(1,2,5,1)$

$(1,2,5,2)$

$(1,2,6)$

$(1,2,6,1)$

$(1,2,6,2)$

$(1,2,6,3)$

$(1,2,7)$

$(1,2,7,1)$

$(1,2,7,2)$

(2)

$(2,1)$

$(2,2)$

$(2,2,1)$

$(2,2,2)$

$(2,2,3)$

$(2,3)$

$(2,4)$

$(2,5)$

$(2,5,1)$

$(2,5,2)$

$(2,5,3)$

$(2,5,4)$

$(2,5,5)$

$(2,6)$

$(2,6,1)$

$(2,6,2)$

$(2,6,3)$

$(2,6,4)$

$(2,6,5)$

$(2,6,6)$

$(2,7)$

$(2,7,1)$

$(2,7,2)$

$(2,7,3)$

$(2,7,4)$

$(2,7,5)$

$(2,7,6)$

$(2,7,7)$

$(2,8)$

$(2,8,1)$

$(2,8,2)$

$(2,8,3)$

$(2,8,4)$

$(2,8,5)$

$(2,9)$

$(2,9,1)$

$(2,9,2)$

$(2,9,3)$

$(2,9,4)$

$(2,9,5)$

$(2,10)$

$(2,10,1)$

$(2,10,2)$

$(2,10,3)$

$(2,10,3,1)$

BASE DATA

BASE DATA/Interviewees

BASE DATA/Interviewees/Gender

BASE DATA/Interviewees/Occupation

BASE DATA/Schools

BASE DATA/Schools/School Type

BASE DATA/Schools/School Type/Secondary

BASE DATA/Schools/School Type/Vocational

BASE DATA/Schools/School Type/Comm./Comp

BASE DATA/Schools/School Size

BASE DATA/Schools/School Size/Large

BASE DATA/Schools/School Size/Small

BASE DATA/Schools/Social Class Mix

BASE DATA/Schools/Social Class Mix/Middle Class

BASE DATA/Schools/Social Class Mix/Working Class

BASE DATA/Schools/Social Class Mix/Mixed

BASE DATA/Schools/Location

BASE DATA/Schools/Location/Urban

BASE DATA/Schools/Location/Rural

BASE DATA/Schools/Disadvantaged Status

BASE DATA/Schools/Disadvantaged Status/Yes

BASE DATA/Schools/Disadvantaged Status/No

BASE DATA/Schools/TY Provision

BASE DATA/Schools/TY Provision/Optional

BASE DATA/Schools/TY Provision/Compulsory

BASE DATA/Schools/TY Provision/Other

BASE DATA/Schools/School LC Performance

BASE DATA/Schools/School LC Performance/Above Average Impact of TY on Performance

BASE DATA/Schools/School LC Performance/Below Average Impact of TY on Performance THEMES

THEMES/Work Duties

THEMES/Leaving Cert Programmes and TY

THEMES/Leaving Cert Programmes and TY/LCA

THEMES/Leaving Cert Programmes and TY/LCVP

THEMES/Leaving Cert Programmes and TY/Regular LC

THEMES/Work Experience

THEMES/Choices

THEMES/Perceptions of TY

THEMES/Perceptions of TY/Subject Choice

THEMES/Perceptions of TY/Who Enters

THEMES/Perceptions of TY/Parents

THEMES/Perceptions of TY/Students

THEMES/Perceptions of TY/Teachers

THEMES/Providing TY

THEMES/Providing TY/Reasons for Introducing

THEMES/Providing TY/Compulsory

THEMES/Providing TY/Optional

THEMES/Providing TY/Other

THEMES/Providing TY/Changing Nature

THEMES/Providing TY/Resources

THEMES/Content

THEMES/Content/Subjects Offered

THEMES/Content/How content is decided

THEMES/Content/Assessment

THEMES/Content/Certification

THEMES/Content/Impact of TY

THEMES/Content/New Content

THEMES/Content/Extra Curricular Activities

THEMES/Work Experience

THEMES/Work Experience/Impact

THEMES/Work Experience/How Much

THEMES/Work Experience/Obtaining Work

THEMES/Work Experience/Career Provision

THEMES/Work Experience/Competition from Other Schools

THEMES/School Ethos

THEMES/School Ethos/Objectives of the School

THEMES/School Ethos/Pastoral Care

THEMES/School Ethos/Future Development of School

THEMES/School Ethos/Streaming

THEMES/School Ethos/Literacy

THEMES/Outcomes

THEMES/Outcomes/Destinations after TY

THEMES/Outcomes/Personal Development

THEMES/Outcomes/Academic Performance

THEMES/Outcomes/Academic Performance/Drop Out

Figure 2. Coding tree from empirical example 2 